\title{
Determination of Some Elements in Gall Stones and Some Natural Samples (Tap Water, Black Tea, and Table Salt ( $\mathrm{Na} \mathrm{Cl}$ ))
}

\section{Hiba HT, Mohammed SA, Ishraga EA and Abdal Salam AD*}

Abdal Salam AD, Department of Chemistry, Faculty of Science, Sudan University of Science and Technology, Khartoum, Sudan *Corresponding Author: Abdal Salam AD, Department of Chemistry, Faculty of Science, Sudan University of Science and Technology, Khartoum, Sudan.

Received: September 26, 2019; Published: November 04, 2019

DOI: $10.31080 /$ ASPS.2019.03.0431

\section{Abstract}

The high amount or decreases in the metal ions consumed in the human body can cause a serious problem on human health. For thesis problem inductively coupled plasma optical emission (ICP) was used to analyze human gallstones elements $\left(\mathrm{Ba}^{2+}, \mathrm{Ca}^{2+}, \mathrm{Cu}^{2+}\right.$, $\mathrm{Fe}^{2+}, \mathrm{K}^{1+}, \mathrm{Mg}^{2+}, \mathrm{Mn}^{2+}, \mathrm{Na}^{1+}$ and $\mathrm{Se}^{2+}$ ) and some natural samples (tab water, black tea and sodium chloride ( $\mathrm{Na} \mathrm{Cl}$ ). Ten gall stones were collected during surgery from patients with cholesterol, pigment and mixed stones. The results of quantitative elemental analysis revealed that, $\mathrm{Ca}^{2+}$ was high in samples 4,5,7,8 and black tea (12), $\mathrm{K}^{1+}$ was high in black tea (12) and Sodium chloride (13), $\mathrm{Mg}^{2+}$ was high in black tea (12) and Sodium chloride (13), $\mathrm{Na}^{1+}$ was high in Sodium chloride (13). The rate of elements $\left(\mathrm{Ca}^{2+}, \mathrm{K}^{1+}, \mathrm{Na}^{1+}, \mathrm{Mg}^{2+}\right)$ were high in black tea and sodium chloride probably that reason indicates the stone formation in the human body.

Keywords: Inductively Coupled Plasma Mass Spectrometry (ICP-MS); Gallstones; Cholesterol Stones; Pigment Stones; Mixed Stones

\section{Introduction}

Gallstones are frequently composed of more than one crystalline compound, although the exact mechanism of formation of multicomponent stones is not clearly understood. They are generally classified into three major types: pure cholesterol, pigment and mixed gallstone. Pigment gallstones are further subdivided into laminated brown stones and amorphous black stones [1]. Cholesterol gallstones are higher prevalence than pigment gallstones. Diet affected the type of gallstone formation. Studies reported that Consumption of fried foods and animal lipid increased risk of cholesterol gallstone formation, while intake of carbohydrate increases risk of pigment gallstones formation. Suggesting diet influenced the type of gallstone formation [2]. Aetiology and pathogenesis of cholesterol gallstones still are not well defined, and strategies for prevention and efficient nonsurgical therapies are missing. This review summarizes current concepts on the pathogenesis of cholesterol gallstones with focus on the uptake and secretion of biliary lipids and special emphasis on recent studies into the genetic background More than $80 \%$ of gallstone carriers are unaware of their gallbladder disease $[3,4]$. Gallstone disease is the most common gastrointestinal disorder affecting the biliary system. Its complications are caused by inflammation, infection, or ductal obstruction. Gallbladder stone disease is one of the major surgical problems in several populations and it accounts for many hospital admissions and surgical interventions. Gallstones represent a major problem in many countries [5]. Deposition of hard fatty or mineral in the gallbladder leads to Gallstone disease. In this disease, the stones block part of biliary system and cause irritation of gallbladder and complications. This disorder can cause life threatening conditions if their symptoms or complications left without treatment [6]. About 1-2\% per year of patients develop complications and need surgery [7]. The prevalence of cholelithiasis in Asian population is estimated to be $3 \%$ to $10 \%$. Published data showed the prevalence of GSD to be 3.2\% in Japan [8], 3 11\% in China [9]. 7.1\% in Northern India [10] and 5\% in Taiwan [11]. In Pakistan, gallstones are found in $8 \%$ and $20 \%$ of patients above 40 and 60 years respectively [12]. In the US, gallstone disease has the most common inpatient diagnosis among gastrointestinal and liver diseases [8] and stands for $\$ 5.8$ billion direct costs, exceeded only by gastro esophageal reflux disease [13]. Cholesterol stones contain more than $70 \%$ of cholesterol whereas pigment stones contain mainly of various bilirubinate salts with less than $20 \%$ cholesterol by weight. Pigment stones are predominant in India [14]. In this study we determine some elements in gall stones and some natural samples (tap water, black tea, and table salt $(\mathrm{Na} \mathrm{Cl})$ we found that the reason of the stone formation in the human body from black tea. 


\section{Materials and Method}

- $\quad$ Samples: Gall stones were collected from 10 Sudanese patients in Sudan. The stones were collected, dried and powdered to homogenous mixture and transferred into plastic containers.

- $\quad$ Chemicals: All chemicals used in this work were of analytical grade type (AR), Hydrochloric acid (36-38\%), Nitric acid (96-72\%), anhydrous potassium bromide, de ionized water.

- $\quad$ Equipment: Mortar, Beakers, volumetric flask.

- Instruments: Varian 725-ES inductively coupled plasma optical emission spectrometer.

- Methods: $(0.5 \mathrm{~g})$ of the collected gall stones was placed into digestive vial and $9 \mathrm{ml}$ of aquilegia $(6 \mathrm{ml} \mathrm{HCl}$ conc. and $2 \mathrm{~mL}$
HNO3 conc.) was added. The volume was then adjusted to 25 $\mathrm{ml}$ by adding water and the mixture was shaken. Na cl sample solution was prepared by dissolving $10 \mathrm{mg}$ of powdered sample in demonized water and diluted to $100 \mathrm{ml}$ with demonized water in volumetric flask. Black tea sample solution was prepared by boiling $10 \mathrm{mg}$ of sample in demonized water; it was filtrated and diluted to $100 \mathrm{ml}$ with demonized water in volumetric flask. All samples were analyzed by inductively coupled plasma optical emission (ICP), varin, and 725-ES.

\section{Results}

The elements content of different gall stones samples tap water, black tea and sodium chloride were as shown in table 1 given by Inductively Coupled Plasma- Optical Emission Spectrometer (ICP), varin, 725-ES.

\begin{tabular}{|c|c|c|c|c|c|c|c|c|c|c|}
\hline Samples & Age & $\mathbf{B a}^{2+}$ & $\mathrm{Ca}^{2+}$ & $\mathrm{Cu}^{2+}$ & $\mathrm{Fe}^{2+}$ & $\mathbf{K}^{1+}$ & $\mathbf{M g}^{2+}$ & $\mathrm{Mn}^{2+}$ & $\mathrm{Na}^{1+}$ & $\mathbf{S e}^{2+}$ \\
\hline Samples 1 & 45 & 43.54 & 52.660 & 35.69 & 20.93 & 0.0318 & 354.0 & 14.3 .7 & 151.2 & 0.0266 \\
\hline Samples 2 & 40 & 0.0005 & 29.310 & 545.6 & 54.61 & 0.0318 & 247.7 & 149.6 & 254.3 & 0.0266 \\
\hline Samples 3 & 54 & 1.569 & 1.371 & 8.776 & 96.75 & 0.031 & 45.37 & 4.117 & 19.57 & 0.0266 \\
\hline Samples 4 & 26 & 1.458 & 732 & 2.893 & 37.14 & 163.8 & 53.11 & 0.3205 & 48.99 & 0.0266 \\
\hline Samples 5 & 68 & 2.881 & 68.620 & 4172 & 1418 & 399 & 1021 & 424.3 & 277.6 & 0.0266 \\
\hline Samples 6 & 53 & 0.0005 & 15.990 & 723.0 & 189.29 & 458.0 & 631.5 & 139.5 & 269.0 & 0.0266 \\
\hline Samples 7 & 45 & 0.0005 & 88.980 & 464.3 & 280.5 & 47.64 & 927.7 & 1131 & 234.3 & 0.0266 \\
\hline Samples 8 & 44 & 0.0005 & 201.000 & 151.9 & 145.7 & 82.38 & 837.4 & 121.1 & 172.1 & 0.0266 \\
\hline Samples 9 & 20 & 0.0005 & 17.710 & 483.8 & 175.8 & 155.8 & 198.7 & 57.4 & 355.6 & 0.0266 \\
\hline Samples 10 & 50 & 0.0005 & 141.300 & 1438 & 325.1 & 386.3 & 2337 & 3025 & 449.1 & 119.1 \\
\hline Samples 11 Tap water & & 0.1813 & 54.66 & 0 & 0.0344 & 5.326 & 18.05 & 0 & 32.38 & 0 \\
\hline Samples 12 Black tea & & 8.7847 & 2192 & 34.35 & 40.24 & 17042 & 1207 & 648.0 & 700 & 12.37 \\
\hline Samples $13 \mathrm{Na} \mathrm{Cl}$ & & 0.9478 & 0.9478 & 0 & 0 & 740 & 1743 & 3.227 & 355000 & 0 \\
\hline
\end{tabular}

Table 1: As we can see, the content average level (in p.p.m).

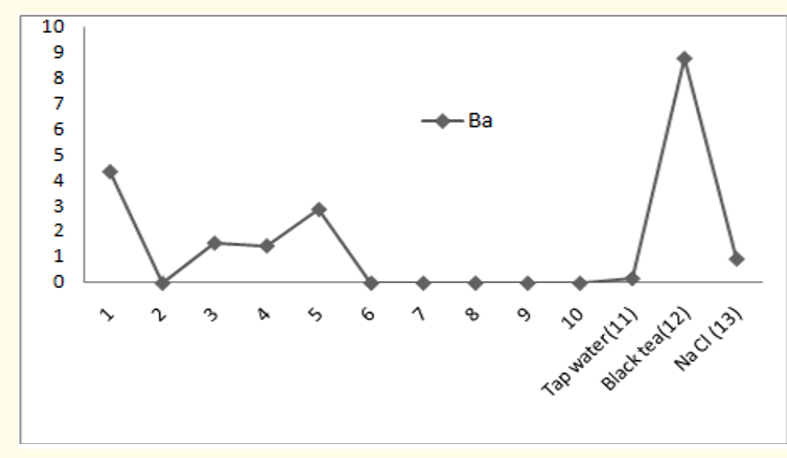

Figure 1: $\mathrm{Ba}^{2+}$ Content (p.p.m) by ICP in sample1-13.

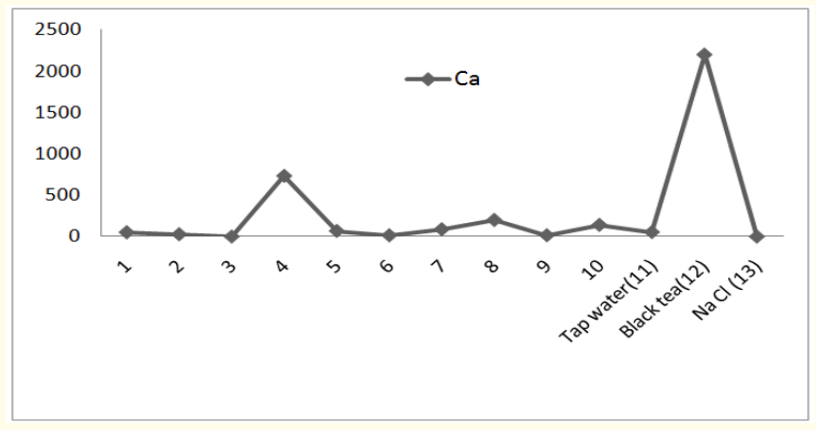

Figure 2: $\mathrm{Ca}^{2+}$ Content (p.p.m) by ICP in sample1-13.. 


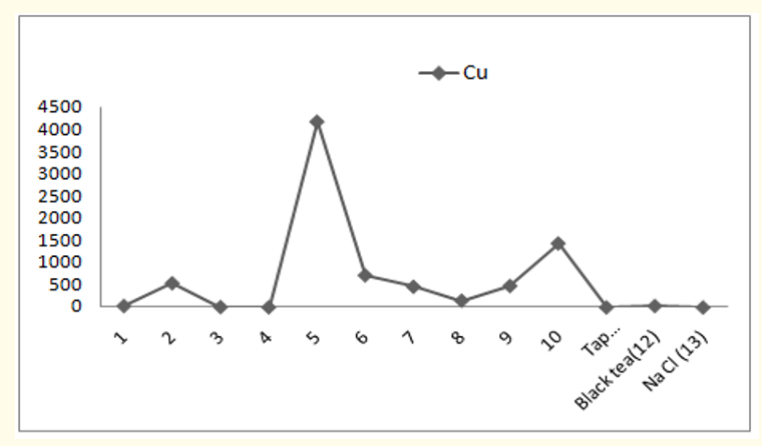

Figure 3: $\mathrm{Cu}^{2+}$ Content (p.p.m) by ICP in sample1-13.

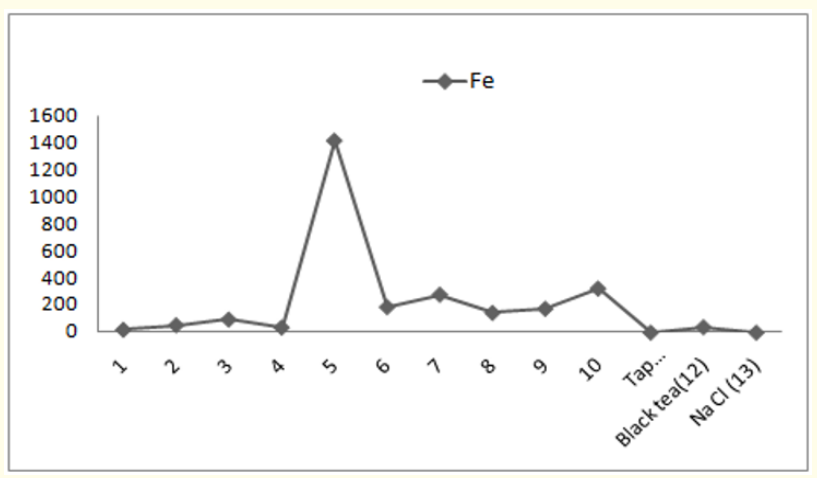

Figure 4: $\mathrm{Fe}^{2+}$ Content (p.p.m) by ICP in sample1-13.

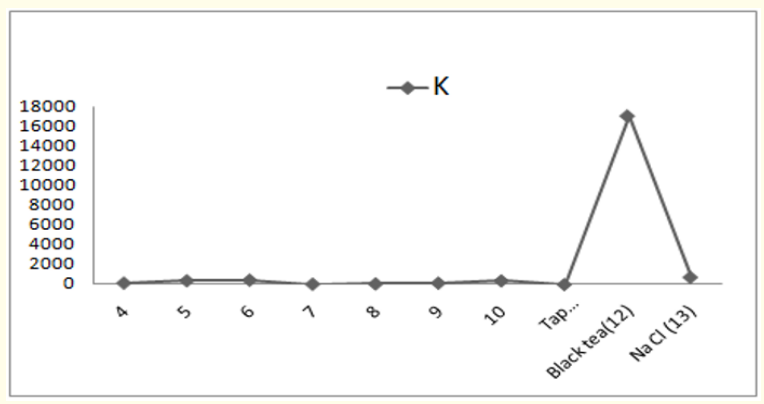

Figure 5: K1+ Content (p.p.m) by ICP in sample1-13.

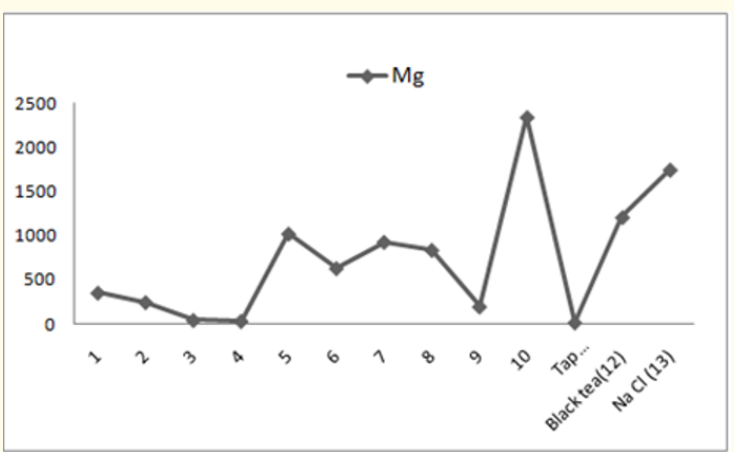

Figure 6: $\mathrm{Mg}^{2+}$ Content (p.p.m) by ICP in sample1-13.

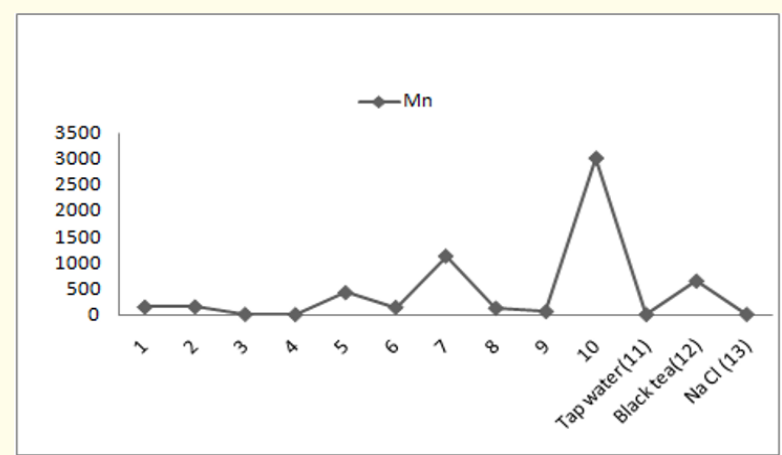

Figure 7: $\mathrm{Mn}^{2+}$ Content (p.p.m) by ICP in sample1-13.

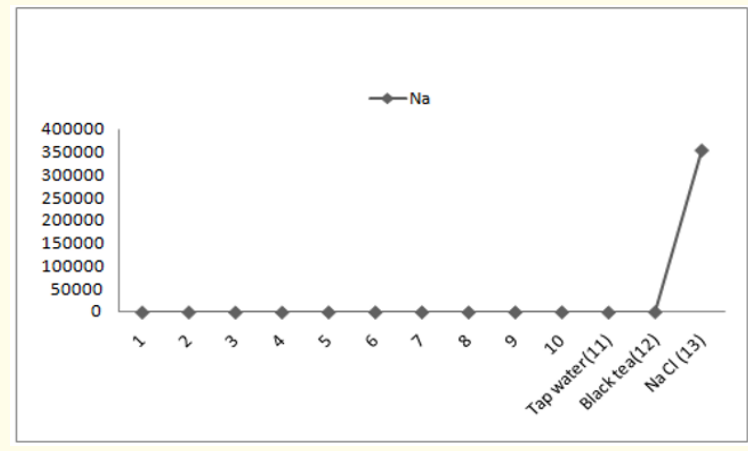

Figure 8: $\mathrm{Na}^{1+}$ Content (p.p.m) by ICP in sample1-1

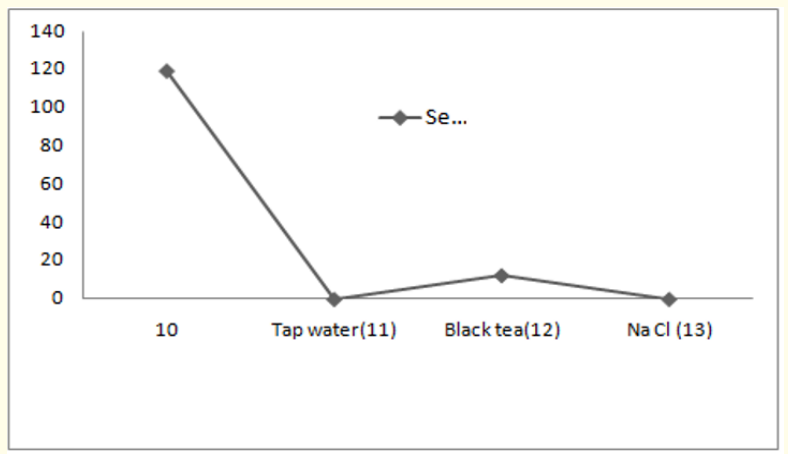

Figure 9: $\mathrm{Se}^{2+}$ Content (p.p.m) by ICP in sample1-13.

\section{Discussion}

The result of elements of the different gall stones samples (110), tap water (1-1), black tea (12), and sodium chloride $(\mathrm{Na} \mathrm{Cl})$ (13), gave indication to the concentration of element, the rate of (Ba) was high in samples $(1,3,4,5$, and black tea (12), the rate of (Ca) was high in samples $(4,5,7,8$ and black tea (12), the rate of $(\mathrm{Cu})$ was high in samples $(2,5,6,9$ and 10 , the rate of $(\mathrm{Fe})$ was high in samples $(5,6,7,9$ and 10$)$. The rate of $(\mathrm{K})$ was high in ample 13 and black tea (12), the rate of $(\mathrm{Mg})$ was high in sample $(10$, black 
tea (12), and sodium chloride (13)) the rate of (Mn) was high in samples $(7,10$, and black tea (12). the rate of Na was high in sodium chloride (13), the rate of (Se) was high in samples (10 and in the black tea (12). The rate of elements ( $\mathrm{Ca}, \mathrm{K}, \mathrm{Na}, \mathrm{Mg}$,) were high in black tea and sodium chloride probably that reason indicates the stone formation. The gallbladder can develop only one large stone or hundreds of small stones, or a combination of the two. Gallstones formation in not related to single reason. Cholesterol stones formed when the liver produces much cholesterol in the bile which form crystals and changed to hard stones in the gallbladder. Pigment stones they differ in their chemical composition and colored (black and brown) by the presence of bilirubin, the pigment in RBCs. They are composed of bilirubin polymers or calcium salts. These stones formed because of changes in bile components or due to inability of gallbladder to empty normally. Pigment stones are associated with chronic hemolysis in conditions such as sickle cell disease, thalassemia, and cirrhosis. Mixed stones composed of cholesterol and salts. These types are the most common. Gallstones formation be 7 come more common with older age, female gender, overweight and diabetic people $[15,16]$.

\section{Conclusion}

The result of the elements concentration of different gall stone samples (1-10), tap water (11), black tea, (12) and sodium chloride (13) gave indication to the concentration of element, the rate of element was high in black tea sample, probably, that was the reason indicate that the stone formation.

\section{Bibliography}

1. Beckingham IJ. "ABC of diseases of liver, pancreas, and biliary system. Gallstone disease". BMJ 322 (2001): 91-94.

2. Bashir M Jarrar and Meshref A Al-Rowaili. “Chemical Composition of Gallstones from Al-Jouf Province of Saudi Arabia". Malaysian Journal of Medical Sciences 18 (2011): 47-52.

3. UAttili AF., et al. "Epidemiology of gallstone disease in Italy: prevalence data of the Multicenter Italian Study on Cholelithiasis (M.I.COL.)". American Journal of Epidemiology 141 (1995): 158-165.

4. Heaton KW., et al. "Symptomatic and silent gall stones in the community". Gut 32 (1991): 316-320.

5. Yomna Ali., et al. "Gallbladder Stone Disease and its Relation to Dietary Intake" (2019).

6. Li Huang., et al. "Farnesoid X-receptor activates transcription of the phospholipid pump MDR3". Journal of Biological Chemistry 278 (2003): 51085-51090.

7. Friedman GD., et al. "Prognosis of gallstones with mild or no symptoms: 25 years of follow-up in a health maintenance organization". Journal of Clinical Epidemiology 42 (1989): 127136.
8. Nomura H., et al. "Prevalence of gallstone disease in a general population of Okinawa, Japan". American Journal of Epidemiology 128 (1988): 598-605.

9. Zhang W., et al. "Epidemiology and risk factors of cholelithiasis". Journal of Surgery Concepts and Practice 16 (2011): 408412.

10. Unisa S., et al. "Population-based study to estimate the prevalence and determine risk factors of gallbladder diseases in the rural Gangetic of North India". HPB (Oxford) 13 (2011): 117125.

11. Chen CH., et al. "Prevalence and risk factors of gallstone disease in an adult population of Taiwan: an epidemiological survey". Journal of Gastroenterology and Hepatology 21 (2006): 17371743.

12. Moerman CJ., et al. "Dietary risk factors for clinically diagnosed gallstones in middle-aged men. A 25-year follow-up study (the Zutphen Study)". Annuals of Epidemiology 4 (1994): 248-254.

13. Sandler RS., et al. "The burden of .selected digestive diseases in the United States". Gastroenterology 122 (2002): 1500-1511.

14. Jayanthi V., et al. "Epidemiology of gallstone disease -top line findings”. Bombay hospital Journal 41 (1999) 495-502.

15. Saad Muhmood Hussain., et al. "Determination of Chemical Composition of Gallbladder Stones and their Association with Induction of Cholangiocarcinoma". Asian Pacific Journal of Cancer Prevention 14 (2013): 6257-6260.

16. Mohammed Helmy Faris Shalayel., et al. "Biochemical composition of gallstones: Do different genders differ". American Journal of Biological Chemistry 1 (2013): 1-6.

Volume 3 Issue 12 December 2019 (C) All rights are reserved by Abdal Salam AD., et al. 